\title{
CLIMATE FRIENDLY ACTIVITIES IN GREEN LEAF HOTEL OPERATIONS
}

\author{
AMPHAI WEJWITHAN ${ }^{1}$, HERMANN KNOFLACHER $^{1} \&$ TANAWAN SINTUNAWA ${ }^{2}$ \\ ${ }^{1}$ Centre of Transport Planning and Traffic Engineering, Institute of Transportation, \\ Vienna University of Technology, Austria \\ ${ }^{2}$ Green Leaf Foundation, Thailand
}

\begin{abstract}
Environmental impacts of hotel operation are the main concerns of Green Leaf Hotels (GLH) in Thailand. Most of the green initiatives of GLH are concerned with waste handling and management, energy and resource efficiencies, carbon emission and environmental awareness. Since emerging trends of responsible tourism are basically concerned with how stakeholders in tourism create, participate and contribute to the minimization of carbon dioxide emissions and of ecological impacts. Green activities are directly related to climate change issues such as cycling tourism, low carbon mobility, green menu, climate friendly food supplies and services, green kitchen, swimmer-friendly pool, and other health and wellness promotion activities. Green activities in GLH were initiated and promoted to motivate stakeholders' participations. At destinations, mobility emits a high fraction of carbon emission, switching from current petroleum-based mobility to renewable energy based of cycling mobility could lead to a significant reduction of carbon emission at destinations. Data was collected from Green Leaf Hotels and members of the Krabi Hotel Association in Thailand in 2017 and collected data was then analysed. It was found that hotels and tourists responded positively to take part in climate friendly mobility of cycling tourism.
\end{abstract}

Keywords: sustainable mobility, climate friendly activity, cycling tourism, green operation, Green Leaf Hotel.

\section{INTRODUCTION}

In the past several decades, tourism was ranked top three foreign exchange earnings for Thailand. In the last 10 years, environmental issues were raised in Thai tourism industry. Environmental impacts from tourism industry were found in every tourist destination around Thailand. Waste water and solid waste generations and discharged, energy and resources were inefficiently used emitting high volume of carbon dioxide to atmosphere. Green hotel operations focused on energy consumption, environmental sustainability and protection, and resource efficiencies.

In the meanwhile, climate change endangers the tourism resources in Thailand; that can reduce and even totally destroy the attractiveness of tourism destinations, for example by a change of temperatures, heavy rainfall, floods, heat and the damage of flora and fauna by droughts or thunderstorms [1]. These changes are already taking place in Thailand.

\section{THAILAND TOURISM}

Tourism is one of the fastest growing industries in the world. In 2015, the United Nations World Tourism Organization (UNWTO), indicated in its highlight report that an increasing number of destinations worldwide have opened up to, and invested to tourism, turning it into a key driver of socio-economic progress through the creation of jobs and enterprises, export revenues, and infrastructure development [2]. Over six decades, tourism has experienced continued expansion and diversification, to be one of the largest and fastest growing economic sectors in the world.

As a result of Thai tourism in 2015 contributed $9.3 \%$ of the kingdom's GDP. Travel and tourism directly supported $2,402,500$ jobs ( $6.3 \%$ of total employment). In 2015 , the total 
contribution of travel and tourism to employment, including jobs indirectly supported by the industry was $15.4 \%$ of total employment $(5,869,500$ jobs). Visitor exports generated $1,678,900$ million Baht (17.9\% of total exports) in 2015. Travel and tourism investment in 2015 was 227.4 billion Baht, or $6.8 \%$ of total investment [3].

Fig. 1 shows the trend of tourist arrivals in Thailand that number of tourists increased from 2011 to 2013 and dropped in 2014 as there was political unrest. In 2011, number of tourist arrival was 19,230,470 tourists and in 2015, number of tourist arrival was 29,923,185 tourists rising more than 10 million tourists in 5 years.

Fig. 2 shows number of hospitality businesses in Thailand in the last 10 years increased from 2,547 properties in 2004 to 10,018 properties in 2014, an average increase of $14.7 \%$ per annum.

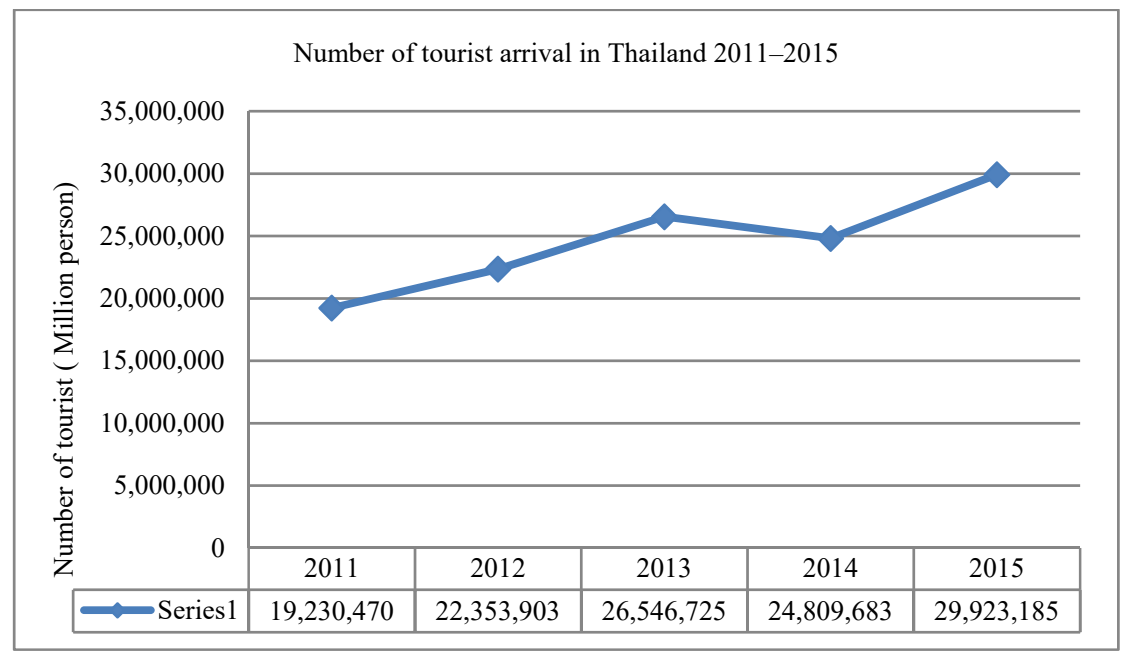

Figure 1: Number of tourists 2011-2015. (Source: TAT Intelligence Centre, Tourism Authority of Thailand, 2015 refer to Department of Tourism, Ministry of Tourism and Sports.)

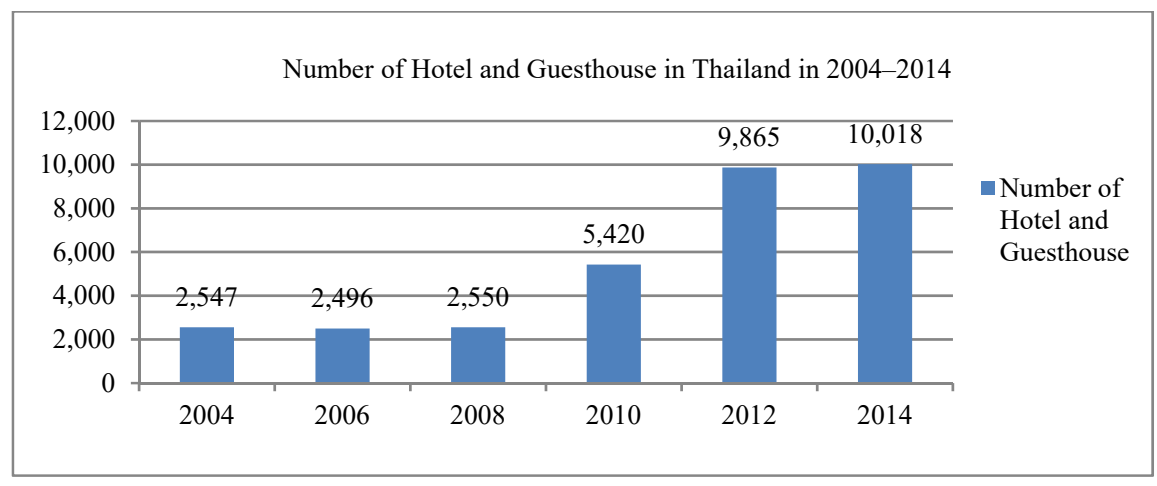

Figure 2: Numbers of hotels and guesthouses in Thailand during 2004-2014. (Source: Hotels and Guest Houses Survey, National Statistical Office, Ministry of Information and Communication Technology.) 
Environmental criteria in Green Leaf standard of the Green Leaf Foundation latest version launched in 2006 focused on imparting knowledge and techniques for boosting the efficiency of environmental preservation activities.

The Green Leaf Certification is an important tool to motivate hotel business and their supply chains in moving toward sustainability such as environmentally friendly aspects of services, responsible consumption and production and social responsibility.

\section{CLIMATE CHANGE AND TOURISM IN THAILAND}

Climate change impacts in the present has a significant number of challenges for tourism with respect to its effects on destinations, infrastructure and resources, generating regions, competitiveness and tourist flows and behaviours, as well as mitigation and adaptation [4]. Climate change is a significant subject of media and public debate. Because tourism is often associated with transport and with aviation in particular, tourism is often a focal point for discussions on climate change in general [5].

Apart from the infrastructure development, Thailand tourism has uncertainly situation with private sector and local community, in order to making initiatives and measurements the carrying capacity of tourism attractions. These are things that vulnerable for changing climate and its effects. Thai tourism situation has faced with the effects of climate change in every year, e.g. water shortage in dry season particular on the island, flooding in the central part of country, high temperature during summer time all over the country. UNWTO says, as with other economic sectors, tourism therefore both contributes to and is affected by climate change [6].

\section{TOURISM AND TRANSPORT IN THAILAND}

Transportation in Thailand is the biggest source of carbon emissions and Thailand is the centre of South East Asia in manufacturing and exporting for car industries under the big car company namely Toyota, Honda, Isuzu, etc., not only for the car but including the accessories and parts of car to be exported from country [7].

Road transport overwhelmingly dominates freight and passenger transport markets, while rail plays a very small and declining role. The majority of Thailand's vehicles use diesel, and fuel economy standards are not applied to gasoline or diesel-powered vehicles. The truck fleet is on average quite old and fuel-inefficient.

Energy intensity in Thailand across the board is not improving. Transport's share of national energy use almost equals that of manufacturing with each representing over a third of the national total. Transport like, manufacturing and other sectors, is an inefficient user of energy compared to selected comparator nations. Further, Thailand's transport sector has not demonstrated a significant improvement in energy use per unit of economic output (i.e. energy intensity) over the past three decades. Transport impacts individual consumers, firms and the public directly and indirectly and in several dimensions. Although transportation services facilitate individuals and firms to access goods and services and to conduct their business, the production of transportation services consumes energy, generates greenhouse gas emissions, and creates air pollution affecting users and the community at large. Moreover, public resources are used to finance transport infrastructure which is expensive and costly to operate and maintain [8].

Table 1 shows road transport mode was the highest energy consumption in Thailand, the trend of fuel consumption is still in the rising mode every year according to a report from Department of Alternative Energy Development and Efficiency (DEDE), Ministry of Energy in 2014. 
Table 1: Energy Consumption by Transport Mode 2009-2013 (ktoe). (Source: Department of Alternative Energy Development and Efficiency, Ministry of Energy, 2014.)

\begin{tabular}{|l|c|c|c|c|c|}
\hline \multicolumn{5}{|c|}{ Energy Consumption by Transport Mode 2009-2013 (ktoe) } \\
\hline Transport Mode & 2009 & 2010 & 2011 & 2012 & 2013 \\
\hline Road & 18,886 & 19,211 & 20,057 & 21,072 & 21,385 \\
\hline Rail & 91 & 88 & 87 & 86 & 92 \\
\hline Waterway & 1,532 & 1,443 & 1,175 & 911 & 920 \\
\hline Air & 3,623 & 3,852 & 4,150 & 4,161 & 4,546 \\
\hline Total & 24,132 & 24,594 & 25,469 & 26,230 & 26,943 \\
\hline
\end{tabular}

Local transport at tourist destinations was dominated by transportation of tourists, and employee in the tourism sector, supply of goods, removal of waste and other related public services. Many tourism destinations are increasingly losing their attractiveness due to increased traffic. Transport improvement for tourism attraction can be addressed follows:

- Capacity utilization and travel management;

- Use of modern engines (e.g. speedboats);

- Non-motorized mobility (e.g. bicycle, walking- instead of motorbike rental).

Non-motorized mode is increasingly and being implemented as an option for sustainable mobility for transport planning in both local and national level. Cycling in Thailand came back on busy roads as the recreation and health promotion activities. Besides, cycling tourism is one of the tourism products that are made up parallel with other types of transport e.g. cars, ferry, air, rail, bike, buses, coach, and van. Green travelling forms in transport are bicycle, foot, horse, canal boat, trekking which have very small impacts on the environment. Results in this paper indicate that cycling tourism as a low carbon tourism activity can be addressed in Thai tourism activities.

\section{METHODOLOGY AND RESULT}

This study interviewed hoteliers in Krabi province located in southern Thailand, Krabi province was selected as a case study because it was known as a popular tourist destination for both domestic and overseas holiday makers, especially for foreigners who are searching for responsible activities in tourist destinations. Cycling tourism was as one choice of tourism activities regarding as green activities.

There were two parts of data collections in this study; one was the secondary data collection from websites reviewed, these online sources were bicycle tourism activities, tours and services such as bicycle rentals and repair services. The second part of data collection was the survey and interviews of members of Krabi Hotel Association.

Krabi is one of the most popular tourist attractions. In this study, online tour programs focusing on bicycle tourism, cycling tourism, eco cycling and adventure cycling in Krabi Province were studied.

The preferred tour types were popular tourism attraction of Krabi province. It was found that $38.24 \%$ of cycling tourists were point-to-point tours and around $25 \%$ was sightseeing biking in combination with trekking and $25 \%$ was a combination of cycling and kayaking as adventure tourism activities, while horse riding is very specific for particular areas such as 
Ao Nang Beach, Nopprat Thara Beach as the lowest combination was as low as $11.76 \%$ of tour programs. Tourists were generally accompanied by their friends and families, while a long-distance bicycle tours were also famous for sport lover groups.

Ao Nang area was the most popular starting point and finishing point of cycling activities. Ao Nang was a centre for tourist facilities and accommodations most tour programs start and end at Ao Nang area. On the other hand, jungle routes were also popular for cycling tourism because combination of cycling and trekking to waterfalls, emerald pond, etc. While Hat Noppharat Thara (Noppharat Thara beach) and Moo Koh Phi Marine Nation Park were promoted as cycling and kayaking day tour. Meanwhile, cycling at Koh Klang was highlighted as community cycling tourism as its uniqueness of local fisherman village, paddy field on the island and beautiful batiks making from residents of this island.

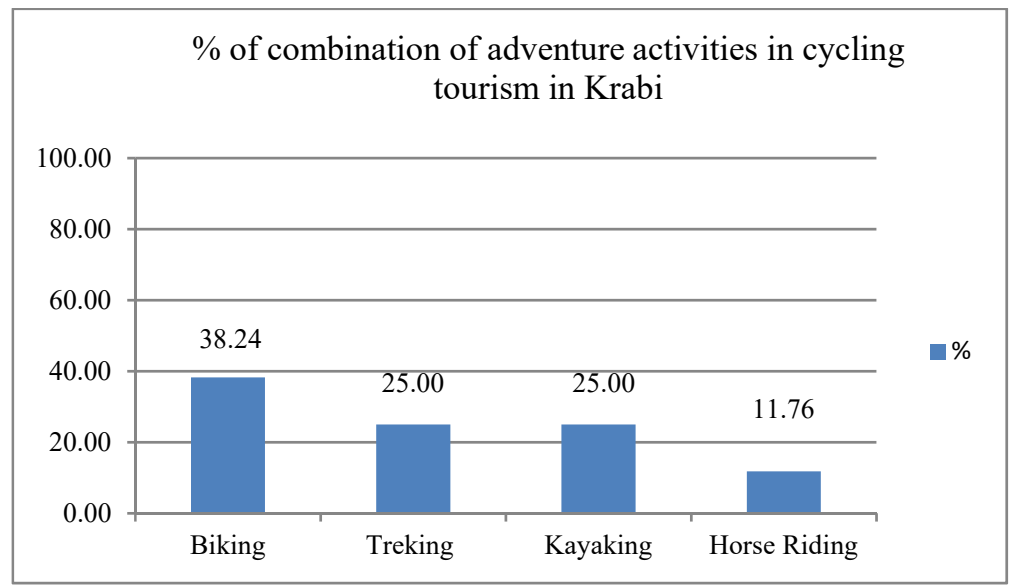

Figure 3: Combination of cycling tourism and other activities.

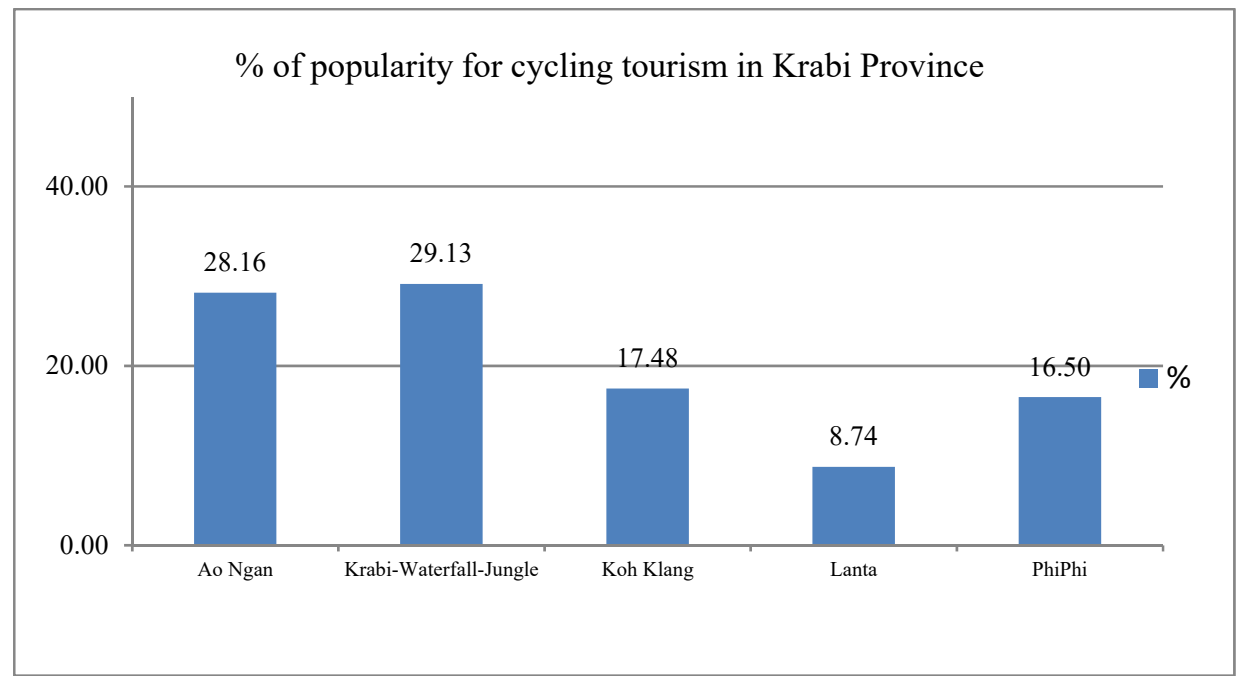

Figure 4: Famous cycling tourism areas in Krabi. 
The second part of survey result showed green activities organized by Green Leaf Foundation's member hotels. The question to be answered was: Were there hotels in Krabi's tourist destinations organizing cycling tour program and activities in their services?

It was found that, there were $33.09 \%$ of respondent hotels were providing bicycle services for guest and $66.91 \%$ of hotel have no bicycle services provision.

It was also found that $18.88 \%$ of responded hotels, that were providing bicycle for their services, wanted to expand the business by increasing number of bicycles for their clients. While $81.12 \%$ of existing bicycle provider hotels were not interested to increase the number of bicycle.

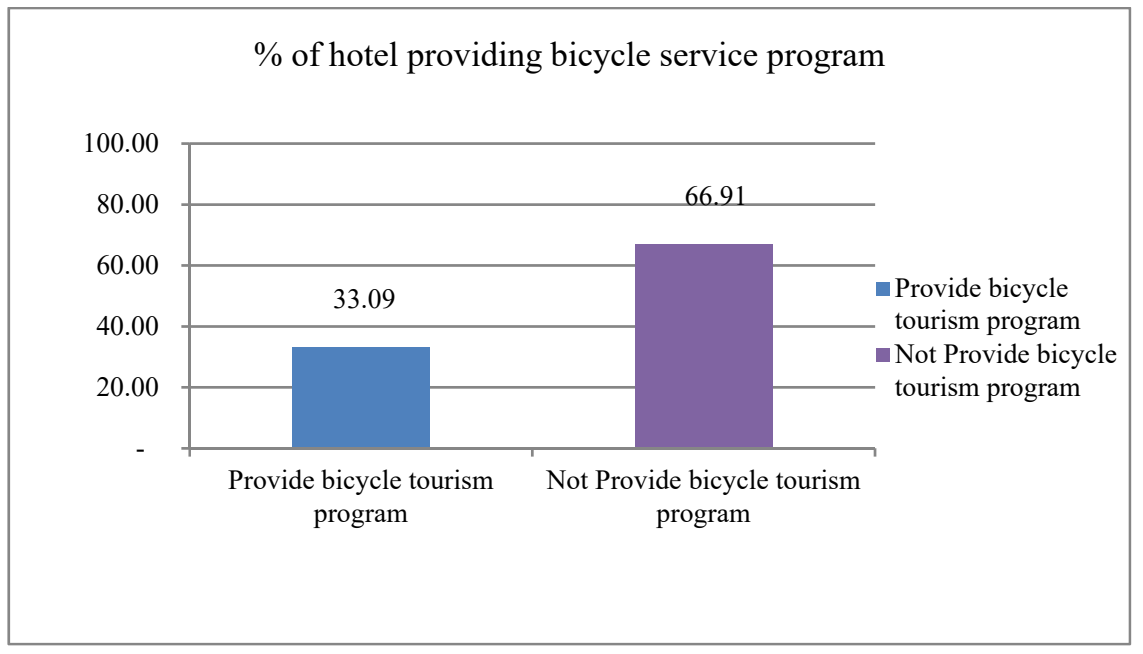

Figure 5: Percentage of hotels providing bicycle services.

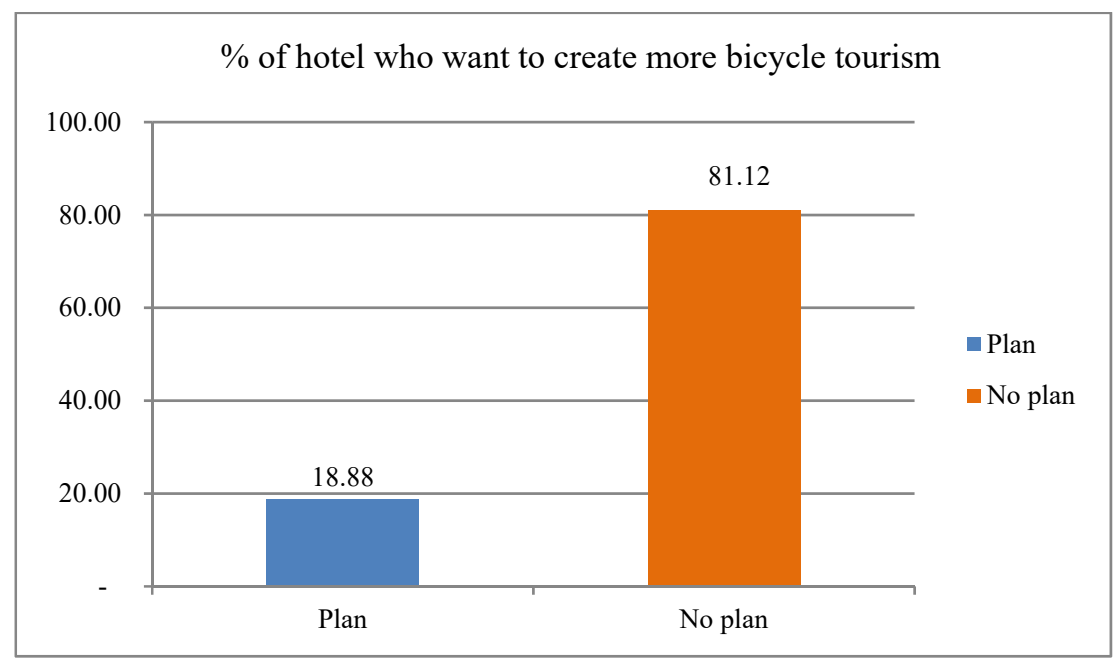

Figure 6: Percentage of hotels wanting to increase number of bicycles. 


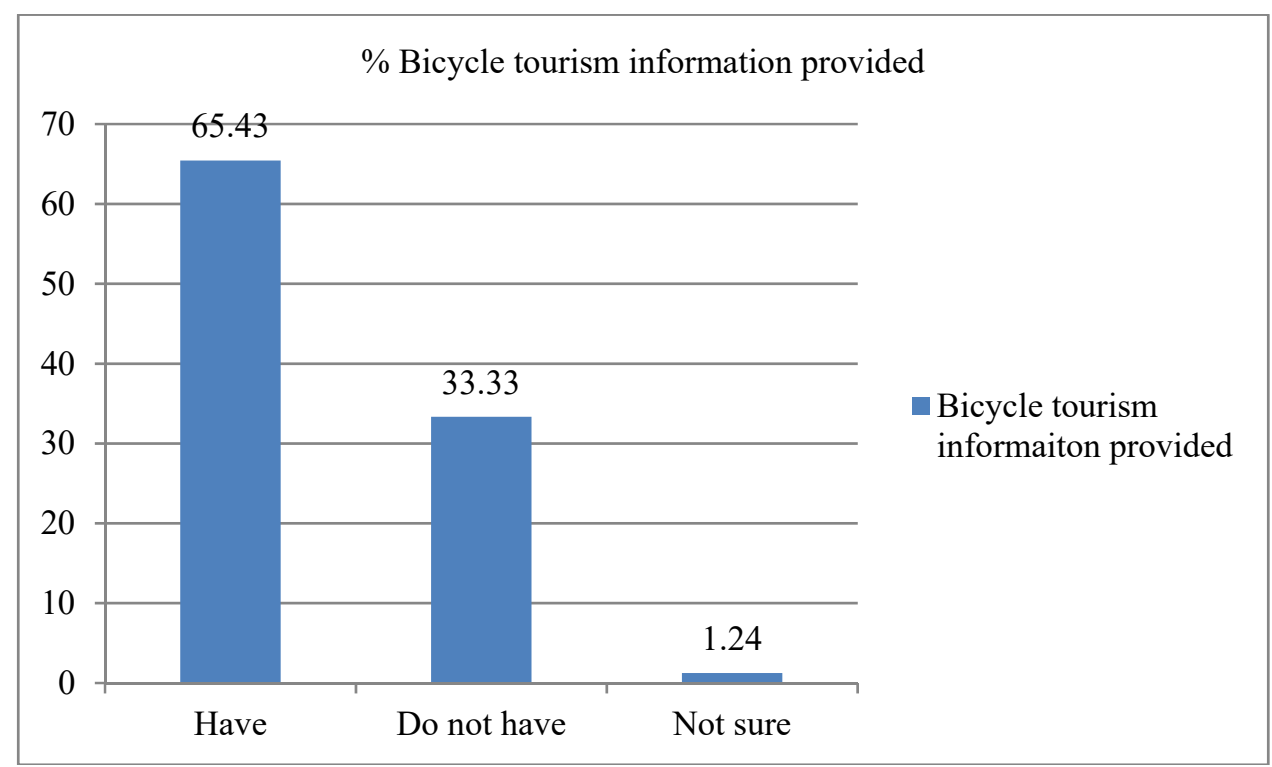

Figure 7: Percentage of hotels providing cycling tourism information.

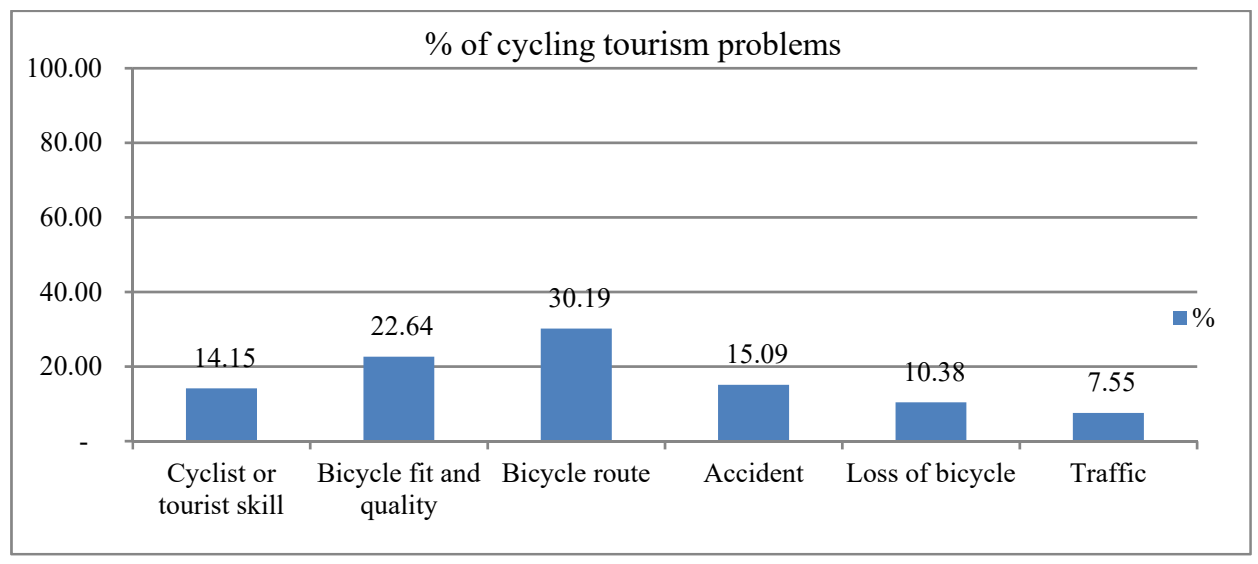

Figure 8: Shows problems in cycling tourism.

Survey results of further questions in this study showed that $65.43 \%$ of responded hotels in this survey were providing cycling tourism information to their guests. Brochures and leaflets were made available at the stands in reception areas. About $33.33 \%$ of respondents did not provide cycling activity information. While the rest $1.24 \%$ of respondents were not sure about the hotel's future management.

It was very informative to learn that hotels with cycling tourism promotion activity received feedbacks from their guests directly. It was found that guest report on cycling tourism problems of quality of bicycle routes, quality of bicycles, cycling accidents, guest cycling skills and confusion of traffic system were $30.19 \%, 22.64 \%, 15.09 \%, 14.15 \%$, and 
Guests reports on accidents and loss of bicycle were $15.09 \%$ and $10.38 \%$ respectively. Nevertheless, it was also found that temperature, rain, wind and traffic density in tourist season were affecting cycling tourism and cyclist's decisions.

Fig. 9 shows many hotels were providing rental motorcycle services instead of bicycle and Fig. 10 shows the quality of road in some cycling routes.

Cycling tourism could be promoted at hotels and could be a source of tourism income. Green Leaf Hotels could use this opportunity to launch corporates social responsibility (CSR) activities by providing free bicycle as their complementary services for guests. Creating low carbon transport in tourism attractions and they can get the positive feedback from their guests as show in Fig. 11.

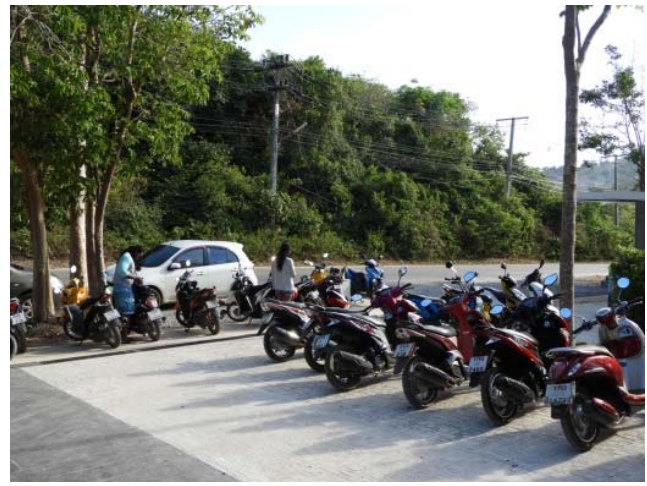

Figure 9: Rental motorcycles for tourists.

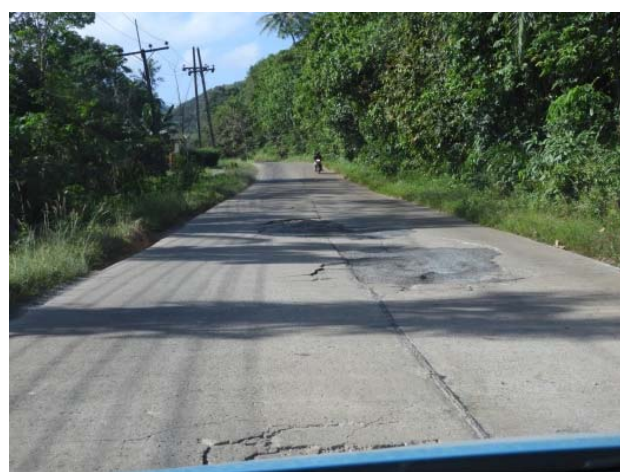

Figure 10: Quality of roads in some cycling routes in Krabi.

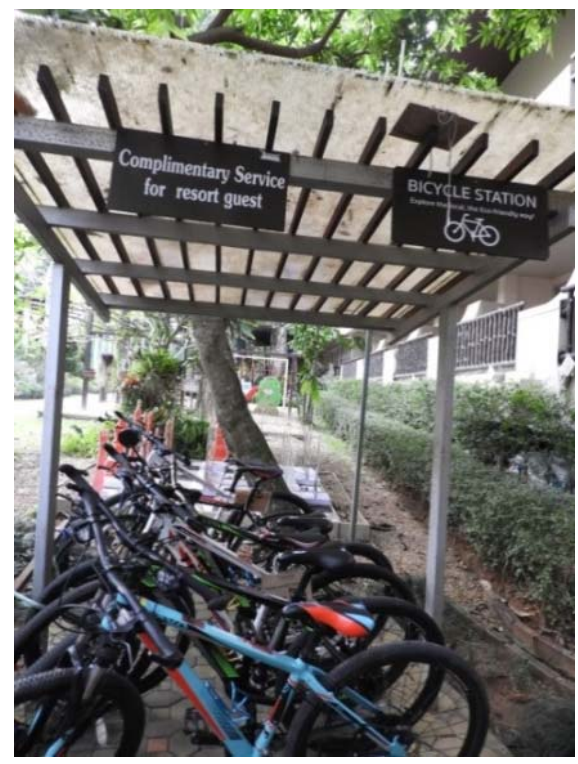

Figure 11: Bicycle station in Pakasai Resort in Krabi. 


\section{CONCLUSION}

Cycling tourism needs cooperation between private sectors and government agencies in order to create and support this low carbon tourism activity at destinations. As the preliminary results showed above, cycling tourism promotion for low carbon tourism activities in Krabi might be achieved. For the economic point of view, cycling tourism is very efficient in both small and large scales of tourism activities. It can be as a small group of tourists visiting attractions contributing to local economy of communities. On the other hand, organizing big events of cycling tourism can also be done similar to marathon running in many cities around the world. These activities can generate income and build the good reputation to tourism attractions. Furthermore, using sustainable mobility by promoting bicycle tourism is one of the leverage activities for sustainable consumption and production to meet the 12th goal of the UNDP Sustainable Development Goals. This action should be encouraged at tourist destinations worldwide.

\section{ACKNOWLEDGEMENTS}

Sincere thank you goes to Green Leaf Foundation and Thai Health Foundation in Thailand for their generous supports to this study. Thanks also go to operators of the Health Promotion and Climate Friendly Bicycle Promotion in tourism attractions project for their continuous encouragement and finally thank you for all respondents in proving relevant data for this study.

\section{REFERENCES}

[1] GIZ Thailand, Guideline Low Carbon Destination Management in Thailand in Close Co-operation with Project Partners of Mu Ko Chang and Related Areas, 2012.

[2] World Tourism Organization, UNWTO Tourism Highlights, 2015 Edition, World Tourism Organization (UNWTO): Madrid, 2015.

[3] World Travel \& Tourism Council (WTTC), Thailand Travel \& Tourism Economic Impacts, 2016, 2016.

[4] World Tourism Organization, Responding to Climate Change - Tourism Initiatives in Asia and the Pacific, UNWTO: Madrid. Hall, C.M. et al., 2005. Gossling, S. and Hall, C.M., 2006. Becken, S. and Hay, J., 2007. Hall, C.M., pp. 131-145, 2010. World Tourism Organization and United Nations Environment Programme, 2008. Scott, D., pp. 17-34, 2011. Scott, D. and Becken, S., 2011. Scott, D. et al., 2012. Gossling, S., Scott, D. and Hall, C.M., pp. 525-538, 2013.

[5] World Tourism Organization, Responding to Climate Change - Tourism Initiatives in Asia and the Pacific, UNWTO: Madrid. Scott, D. et al., 2012. Scott, D. and Lemieux, C. 2009.

[6] World Tourism Organization, Responding to Climate Change - Tourism Initiatives in Asia and the Pacific, UNWTO: Madrid, 2014.

[7] National Statistical Office of Thailand, 2010.

[8] The World Bank and NESDB, Thailand: Green Transport Policy Directions, 2013. 